\title{
NILAI KEARIFAN LOKAL DALAM UPACARA ADAT RITUS TIWU PANGANTEN DI KECAMATAN BABAKAN KABUPATEN CIREBON (Analisis Struktural-Semiotik)
}

\author{
Fiet Haryadi \\ SMP Negeri 1 Pabuaran Cirebon
}

Poe-el: Fiet_soenda77@yahoo.com

\begin{abstract}
Abstrak
Kebudayaan identik dengan kesenian, upacara-upacara adat yang dilaksanakan oleh beberapa kelompok suku bangsa, pakaian adat, cerita rakyat atau legenda serta kesusastraan. Kebudayaan juga sering dikaitkan dengan segala hal yang tradisional. Salah satu contohh kebudayaan yang melekat di masyarakat Sunda, khususnya di Kecamatan Babakan Kabupaten Cirebon yaitu Upacara Adat Ritus Tiwu Panganten (UARTP). UARTP yaitu upacara iringiringan pengantin tebu yang diarak dari balai pertamuan Pabrik Gula Tersana Baru sampai ke dalam Pabrik Gula Tersana Baru. Dalam UARTP mengandung unsur struktural yang merupakan susunan acara dalam kegiatannya, serta mengandung unsur semiotik yaitu ikon, indeks, simbol, alat, dan pelaku. Selain unsur structural-semiotik, UARTP juga mempunyai nilai kearifan lokal. Metode yang digunakan dalam penelitian ini yaitu metode deskriptif. Yang dideskripsikannya adalah tentang nilai kearifan lokal dalam UARTP dikaji dari unsur struktural semiotiknya. Setelah dianalisis, nilai-nilai yang terdapat dalam UARTP yaitu nilai kesejahteraan, kerja keras, disiplin, pendidikan, kesehatan, gotong royong, pengelolaan gender, pemeliharaan budaya, perduli lingkungan, ketenteraman, sopan santun, kejujuran, kesetiakawanan sosial, kerukunan dan penyelesaian konflik, komitmen, pikiran positif, dan rasa syukur. Konsép yang terdapat dalam UARTP, yaitu konsep- konsep permainan, folklor, ritus, mite, punduh, magi, teater. Fungsi yang terdapat dalam UARTP yaitu fungsi hiburan (rekreatif), alat pengesahan pranata-pranata dan lembaga-lembaga kebudayaan (kultural), alat pendidikan anak (edukatif), dan alat pemaksa atau pangawas agar norma-norma masyarakat akan terpanuhi (sosial). Unsur semiotik yang terdapat dalam UARTP yaitu unsur ikon, indeks, dan simbol.
\end{abstract}

Kata Kunci: kearifan lokal, UARTP, struktural semiotik

\section{THE VALUES OF LOCAL WISDOM IN THE CEREMONIAL RITES OF SUGARCAN IN BABAKAN SUBDISTRICT OF CIREBON DISTRICT (A Structural Analysis Semiotic)}

\begin{abstract}
Culture is identical to artistry, indigenous ceremonies carried out by some ethnic groups, custom clothing, folk tales or legends and literatures. Culture is often associated with all things traditional. One form of Sundanese culture, especially in Babakan subdistrict of Cirebon district is the Traditional Ceremony of Bride's Sugarcane Rite. This is a parade ceremony of sugarcane bride from New Tersana meeting hall to the New Tersana building. This ceremony contains structural elements in the form of programs. It also comprises elements of semiotics, which include icons, indexes, symbols, tools and actors. In addition, the ceremony contains local wisdom. The method used in this research is a descriptive method. It delineates the local wisdom extracted from the ceremony by examining semiotic structural elements. Results indicate that the ceremony has many values namely hardworking,
\end{abstract}


discipline, education, health, mutual-cooperation, management of gender, cultural preservation, environmental care, security, courtesy, honesty, social solidarity, harmony and conflict resolution, commitment, positive thoughts and gratitude. The concepts identifiable in the ceremony include the concepts of games, folklores, rite, mites, punduh, magi, and theater. The ceremony has the following functions: entertainment (recreational), instrument of ratification and cultural institutions (cultural), children education tools (educational), and corecive tools to ensure that societal norms are met (social). The semiotic elements found in the ceremony are icon, indexes and symbols.

Keywords: local wisdom, the traditional ceremony of bride's sugarcane rite, structural semiotics.

\section{PENDAHULUAN}

Kebudayaan adalah hasil dari cipta, rasa, karya manusia untuk mendapatkan kesenangan dan kenikmatan dari hasil akal pemikiran manusia. Budaya sendiri dibentuk oleh unsur-unsur yang bersifat universal. Menurut Koentjaraningrat (2009:165) unsur yang membentuk kebudayaan ada tujuh, yaitu 1) sistem religi, 2) sistem organisasi kemasyarakatan, 3) sistem pengetahuan, 4) bahasa lisan dan tulisan, 5) kesenian, 6) sistem mata pencarian, dan 7) sistem teknologi dan alat. Semua unsur merupakan cerminan dari kehidupan masyarakat.

Kebudayaan yang ada di masyarakat akan berbeda antara masyarakat satu dengan masyarakat yang lainnya, sebab kebudayaan bersifat dinamis sesuai dengan perkembangan jaman. Salah satu masyarakat yang mempunyai kebudayaan dinamis adalah masyarakat Sunda. Dalam kebudayaan Sunda kaya akan kearifan lokal. Kearifan lokal adalah nilai dan norma budaya yang merupakan warisan nenek moyang yang berdasarkan fungsinya dalam kehidupan sosial masyarakatnya (Deanastasia tersedia dalam www. kaarifan lokal wikapedia.com.2011). Jenis-jenis kearifan lokal di antaranya: 1) kesejahteraan, 2) kerja keras, 3) disiplin, 4) pendidikan, 5) kesehatan, 6) gotong royong, 7) pengelolaan gender, 8) memelihara budaya, 9) perduli lingkungan, 10) ketenteraman, 11) sopan santun, 12) kejujuran, 13) kesetiakawanan sosial, 14) kerukunan dan cara menyelesaikan konflik,
15) komitmen,16) pikiran positif, dan 17) rasa syukur.

Folklor merupakan salah satu hasil dari kebudayaan. Endraswara (2012:58) menjelaskan bahwa kata folklor berasal dari kata folk dan lore, yang mempunyai arti kolektif. Folk bisa diartikan rakyat dan lore diartikan tradisi. Jadi, folklor yaitu salah satu bentuk/wujud tradisi rakyat.

Jan Harold Brunvand (dalam Danandjaja, 2002:21-22) membagi folklor menjadi tiga bentuk yaitu: (1) verbal folklor (folklor lisan), yaitu folklor yang murni berbentuk lisan, contohhnya ungkapan, peribahasa, pantun; (2) partly verbal folklor (folklor satengah lisan) yaitu folklor campuran antara folklor lisan dan non-lisan, contohnya, tahayul, pesta rakyat, upacara, tari rakyat, teater rakyat; dan (3) non verbal folklor (folklor non-lisan) yaitu folklor yang bentuknya tulisan, contohnya novel dan cerpen.

Menurut Wiliam R. Bascom (dalam Pudentia, (2008:364), folklor mempunyai empat fungsi yaitu sebagai bentuk hiburan (rekreatif), alat pangesahan pranata-pranata dengan lembaga-lembaga kabudayaan (kultural), alat pendidikan anak (edukatif), dan alat pamaksa atau pangawas supaya norma-norma masyarakat yang akan terpenuhi (sosial).

Upacara Adat Ritus Tebu Pengantin (seterusnya disingkat UARTP) adalah salah satu kebudayaan setenganh lisan yang ada di Tatar Sunda, khususna di Kacamatan Babakan Kabupaten Cirebon. UARTP adalah upacara pengantin tebu yang 
diarak/diiring dari Gedung Sanggar Madu (Balai Pertemuan PG Tersana Baru) sampai ke halaman PG Tersana Baru. Dalam struktur susunan acara kegiatannya, UARTP mempunyai unsur-unsur tanda yang secara tidak langsung ingin dikomunikasikan kapada masyarakat umum.

Secara etimologis strukturalisme berasal dari kata struktur artinya adanya hubungan yang tetap antara kelompokkelompok gejala atau unsur (elements).

Unsur tanda menurut Peirce (dalam Sudjiman dan Zoest, 1996:7) adalah sarana manusia dalam berkomunikasi, dengan adanya tanda akan memberikan makna kepada semua hal yang nampak di muka bumi.

Pierce (dalam Santosa, 1993:10) membagi semiotik (tanda) ke dalam tiga jenis yaitu: 1) ikon, yaitu suatu hal yang melaksanakan fungsinya selaku penanda yang serupa dengan objeknya (saperti dalam gambar atau lukisan); (2) indeks, yaitu suatu hal yang melaksanakan fungsinya selaku penanda yang memberi isyarat terhadap tandanya; dan (3) simbol, yaitu suatu hal yang melaksanakan fungsinya selaku penanda yang sacara konvensi sudah biasa digunakeun di masyarakat.

\section{METODE}

Metode yang digunakan dalam penelitian ini adalah metode deskriptif analitik. Adapun prosedur yang digunakan dalam metode ini adalah (1) mengumpulkan data, (2) analisis data, (3) menafsirkan data. Adapun tekhnik yang digunakan dalam penelitian ini adalah (1) tekhnik survei, (2) tekhnik wawancara, (3) angket, (4) observasi, dan (5) tekhnik tes, yang meliputi studi kasus, studi kooperatif dan operasional. Tujuan menggunakan metode deskriptif dalam penelitian ini adalah untuk menganalisis dan mendeskripsikan caracara UARTP di Pabrik Gula Tersana Baru Kacamatan Babakan Kabupaten Cirebon.

Dalam penelitian ini digunakan beberapa instrumen di antaranya sistem narasi. Sistem narasi adalah keseluruhan informasi-informasi dari para tokoh masyarakat, sesepuh pabrik gula, panitia acara atau masyarakat umum tentang bentuk struktural dan semiotik yang ada dalam upacara adat Ritus Tebu Pangantin. Secara keilmuan, unsur strukural dan semiotik bisa dikumpulkan berdasarkan pendapat paraahli sastra dalam buku-buku sumber keilmuan. Untuk menguatkan penelitian ini, maka digunakan pula pedoman observasi, pedoman wawancara, angket penelitian, dan kartu data.

Untuk memudahkan dalam proses penelitian, digunakan pula desain penelitian. Adapun desain yang digunakan dapat terlihat dalam bagan berikut.

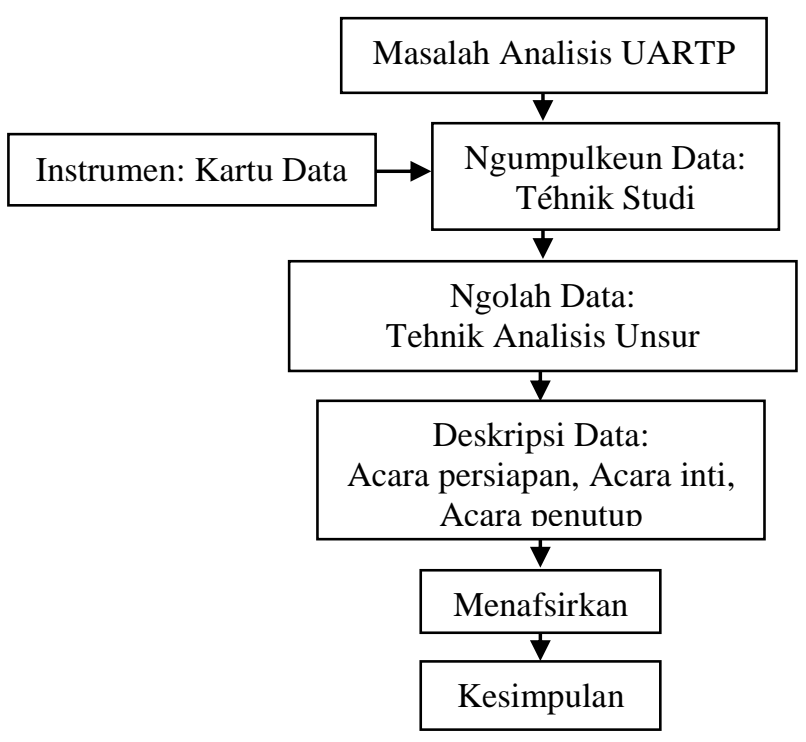

Bagan Desain Panalungtikan

HASIL DAN PEMBAHASAN

Sejarah Upacara Adat Ritus Tiwu

Panganten

Upacara adat menyambut Tiwu Panganten atau babacakan (UARTP) belum bisa dipastikan sejak kapan ada, tapi menurut keterangan sesepuh (punduh), istilah "Tiwu Pangantén" bermula dari "Pangantén Tiwu". Perubahan istilah itu sendiri terjadi ketika pelaksanaan upacara 
ini yang menjadi pengantinnya adalah sepasang jajaka dan wanoja (palaku panganten tiwu). Setelah upacara selesai, jajaka dan wanoja yang menjadi pengantin mendadak menjadi 'tidak waras', bahkan tak jarang yang menjadi pengantinya meninggal dunia.

Adanya kejadian tersebut membuat sesepuh, berpikir untuk menggantikan pelaku dalam upacara ini. Pelaku atau pengantin yang semula sepasang manusia, setelah kejadian itu diganti menjadi sepasang tebu yang dikawinkan, yang kemudian memunculkan atau perubahan istilah yang semula "Panganten Tiwu" menjadi "Tiwu Pangantén".

Dalam pelaksanaanya upacara ini pun dilengkapi oleh beberapa prosesi yang dianggap 'keramat' di antaranya adalah babacakan. Kata babacakan sendiri berasal dari kata 'balakécrakan' (basa Sunda), "bala" artinya batur, "kécrakan" artinya ramai, gembira. Jadi, kata balakécrakan disingkat jadi bakécakan yang kemudian berubah menjadi babacakan (sukuran sambil makan bersama).

Menurut riwayat, upacara babacakan diadakan waktu jaman pemerintah Belanda tepatnya pada tahun 1937. Tujuan diadakannya upacara ini tidak lepas dari masalah perekonomian dan kepentingan Belanda. Belanda berkilah bahwa jika diadakan upacara babacakan, yang sejatinya adalah makan bersama akan menghamburkan uang karyawan. Dengan habisnya uang tersebut, maka karyawan selamanya akan bergantung pada pemerintah Belanda.

Seiring dengan perkembangan zaman, perubahan sistem kepemerintahan dan perubahan kepentingan upacara babacakan masa sekarang dilaksanakan sebagai bentuk rasa syukur terhadap Tuhan Yang Maha Kuasa. Tujuan tersebut terlukisakan dalam iring-iringan karnaval yang penuh dengan nilai-nilai budaya yang harus dipertahankan.

\section{Analisis Struktural UARTP}

1) Waktu Upacara Adat Ritus Tiwu Panganten

\section{Acara Tatahar}

a. Acara Nyuguh tahun sebelum tahun 2000 dilaksanakan pukul 19.30 (ba'da isya) sampai pukul 22.00. Tahun 2001 sampai dengan sekarang dimulai dari pukul 19.30 (ba'da isya) sampai pukul 22.00.

b. Acara Melékan (Lék-lékan) sebelum tahun 2000 dilaksanakan pukul 20.00 sampai pukul 04.30 (subuh). Tahun 2001 sampai dengan sekarang dari pukul 20.00 sampai pukul 04.30 (subuh).

c. Acara Nyabut Tiwu Indung dari tahun 2000 ke belakang dan tahun 2001 sampai sekarang dari pukul 08.00 sampai dengan pukul 10.00 (satu hari sebelum pencabutan tiwu indung secara simbolik), pukul 08.00 sampai pukul 10.00 .

\section{Acara Inti}

a. Pelaksanaan UARTP di Kecamatan Babakan Kabupaten Cirebon, sebelum tahun 2000 dilaksanakan dari pukul 07.00 sampai dengan pukul 11.00. Tahun 2001 sampai dengan sekarang yaitu dari pukul 07.00 sampai pukul 10.00.

b. Upacara Serah Tarima Tiwu Pangantén.

Sebelum tahun 2000 dilaksanakan dari pukul 11.00 sampai pukul12.00. Tahun 2001 sampai sekarang dilaksanakan pada pukul 10.00 sampai pukul 11.00.

\section{Acara Panutup}

Sebelum tahun 2000 dilaksanakan pukul 13.00 sampai pukul 15.00. Tahun 2001 sampai sekarang dilaksanakan pukul 11.00 sampai pukul 13.00 . 


\section{2) Tempat Upacara Adat Ritus Tiwu Panganten Acara Tatahar}

a) Acara Nyuguh

Tahun 2000 dan sebelumnya, tempat nyuguh dilaksanakan di dua tempat yaitu di dalam pabrik gula dan di kebun tebu. Tahun 2001 sampai sekarang, tempat nyuguh dilaksanakan hanya di kebun tebu.

b) Acara Melékan (Lék-lékan)

Acara Melékan pada tahun 2000 ke belakang dilaksanakan dibeberapa tempat di antaraya:
(a) Bale Desa Babakan Gebang (tempat iring-iringan tiwu Panganten).

(b) Balandongan di kebun tebu.

(c) Di dalam pabrik gula.

Acara Melékan pada tahun 2001 sampai sekarang dilaksanakan di:
(a) Gedong Sanggar Madu.
(b) Balandongan kebun tebu.
(c) Di dalam pabrik gula.

c) Acara Nyabut Tiwu Indung

Acara Nyabut Tiwu Indung pada tahun dari dulu sampai sampai sekarang tetap sama dilaksanakeun di kebun tebu.

\section{Acara Inti}

Sebelum tahun 2000 acara inti dilaksanakan di dua tempat yaitu di Alun-Alun Desa Babakan Gebang Kecamatan Babakan Kabupaten Cirebon (tempat persiapan iring-iringan Panganten Tiwu) dan halaman Pabrik Gula Tersana Baru, tempat UARTP dilaksanakan.

Sejak tahun 2001 sampai sekarang acara inti dilaksanakan di dua tempat yaitu di Gedong Sanggar Madu (tempat persiapan iring-iringan Panganten Tiwu) dan halaman Pabrik Gula Tersana Baru (di depan lawang sekéteng) tempat UARTP dilaksanakan.

\section{Acara Penutup}

Sejak dulu sampai sekarang acara penutupan dilaksankan di tiga tempat yaitu:

a) Di kebon tiwu (acara lék-lékandan pencabutan tiwu indung) ditutup oleh upacara babacakan.

b) Di halaman PG Tersana Baru (acara iring-iringan tiwu Pangantendan upacara adat) ditutup oleh acara serah terima tiwu Pangantendari perwakilan tani ke Aparatur PG tersana Baru.

c) Di dalam Pabrik Gula Tersana Baru yaitu tempat acara tahlilan yang ditutup oleh do'a.

\section{3) Pelaku jeung Alat UARTP}

Sejak dahulu sampai dengan sekarang dalam UARTP ada pelaku dan alat upacara yang digunakan.

\section{(1) Pelaku Upacara}

Ada beberapa pelaku upacara yang ada dalam acara UARTP tahun 2000 ke belakang yaitu:

a) Unsur adat tradisional meliputi:
(a) sesepuh (punduh);
(b) saurang jawara;
(c) mang léngsér;
(d) pager ayu (jumlahnya bebas asal genap);
(e) ponggawa (dua atau empat orang); dan
(f) gulang-gulang (jumlahnya bebas asal genap).

b) Unsur Pemerintah/Instansi
(a) Administratur Pabrik Gula Tersana Baru dan Stafna
(b) MUSPIKA Kecamatan Babakan
(c) Instansi lainnya yang berkaitan dan program Bimnas TRI

c) Unsur Masyarakat
(a) Perwakilan Kelompok Tani TRI
(b) Peninjau
(c) Masyarakat Babakan dan sekitarnya.

Sedang pada taun 2001 sampai sekarang pelaku dalam UARTP yaitu: 
a) Unsur adat tradisional meliputi:
(a) sesepuh (punduh);
(b) saurang jawara;
(c) mang léngsér;
(d) pager ayu (jumlahnya bebas asal genap);
(e) ponggawa (dua atau empat orang); dan
(f) gulang-gulang (jumlahnya bebas asal genap).

b) Unsur Pameréntahan/Instansi
(a) Administratur Pabrik
Gula Tersana Baru jeung Srafna
(b) MUSPIKA Kecamatan Babakan
(c) Instansi lainnya yang berkaitan dan program Bimnas TRI

c) Unsur Masyarakat
(a) Perwakilan Kelompok Tani TRI
(b) Masyarakat Babakan dan

\section{(2) Alat Upacara}

Selain pelaku, dalam upacara inipun menggunakan alat-alat yang melengkapi prosesi UARTP. Ini bias dilihat berdasarkan tahunpelaksaaan. Pada tahun 2000 ke belakang alat-alat yang digunakan dalam upacara ini yaitu:

a) Sesajen yang disediakan di antaranya:
(a) kepala kerbau (dua);
(b) tumpeng;
(c) jajanan tujuh warna serumpun;
(d) minuman dan rokok; dan
(e) kembang tujuh rupa serumpun.

b) Alat pendukung lainnya yaitu:

(a) tebu induk (satu);

(b) sepasang tebu pengantin yang dijadikan dari tebu induk (tebu paling bagus);

(c) tebu pengantin pengiring dari setiap kecamatan wilayah tebang;

(d) lima tebu pengiring tambahan;

(e) bunga untuk sawer tebu pangantin; dan

(f) alat kasenian di antaranya: (1) gamelan degung, untuk mengiringi pelaku upacara adat;

(2) kacapi suling pikeun mengiringi kidung; dan (3) kasenian burok, marching band, barongsai, marawis/genjring, réog, angklung, sebagai bentuk penghibur dalam karnaval.

Sedang pada taun 2001 sampai sekarang UARTP menggunakan beberapa alat-alat diantaranya:

a) Sesajen yang disediakan di antaranya:

(a) tumpeng;

(b) jajanan tujuh warna serumpun; dan

(c) minuman dan rokok

b) Alat pendukung di antaranya:

a) tebu induk (hiji);

b) sepasang tebu pangantin (tebu paling bagus);

c) tebu pengantin pengiring dari setiap kecamatan wilayah tebang;

d) bunga untuk sawer tebu pangantin; dan

e) alat kesenian lainnya di antaranya: (1) gamelan degung, untuk mengiringi pelaku upacara adat; (2) kacapi suling untuk mengiringi kidung; dan (3) kesenian burok, marching band, barongsai, marawis/ genjring, reog, angklung, sebagai bentuk penghibur dalam karnaval.

Konsep dan Fungsi UARTP di Kecamatan Babakan Kabupaten Cirebon a. Konsep Kaulinan

UARTP tidak termasuk pada konsep kaulinan (permainan) sebab UARTP merupakan satu kegiatana sakral/suci, bukan kegiatan bermain.

\section{b. Konsep Folklor}

Uapacara Adat Ritus Tiwu Panganten dalam studi folklor termasuk pada golongan 
folklor sebab berkembang dan diwariskan secara lisan.

\section{c. Konsep Ritus}

Sesuai dengan pengertian ritus di atas, sudah tentu bahwa UARTP merupakan upacara ritual sebab susunan acaranya memiliki tahapan-tahapan ritual khusus dalam acara nyuguh dan salamétan.

\section{d. Konsep Mite}

Acara nyuguh melambangkan bahwa UARTP memiliki nilai rasa penghormatan kepada paraarwah dan penunggu Pabrik Gula Tersana Baru.

\section{e. Konsep Shaman (Punduh)}

Dalam UARTP acara nyuguh dipimpin oleh satu orang yaitu punduh.

\section{f. Konsep Kejawén}

UARTP merupakan upacara kegiatan yang mengandung konsep kejawen, hal ini terbukti dengan adanya upacara penghormatan untuk arwah yang menempati mesin giling "Si Doblang" dan arwah Ibu Sari serta para arwah-arwah lainnya yang dipercaya ada di Pabrik Gula Tersana Baru.

\section{g. Konsep Magis}

Magis yaitu segala sistem tingkah laku manusia (termasuk abstraksi-abstraksi dalam tindakan) untuk memenuhi satu maksud melalui kekuatan-kekuatan yang ada di alam, serta semua kompleks anggapan yang melatarbelakanginya. Konsep magis dalam UARTP terbukti pada suatu kejadian dan kejanggalan semisal pada tahun 2004 Pabrik Gula Tersana Baru dalam menghadapi panen tebu tidak melaksanakan UARTP, dan yang terjadi pembantu General Manager mendadak kerasukan. Dalam kerasukan itu dia mengatakan "Aing hayang aya raraméan, hayang aya hiburan". Mendadak General Manager mengundang punduh untuk menerjemahkan maksud perkataan pembantu tadi. Punduh memberi pernyataan bahwa UARTP harus dilaksanakan kembali. Mendadak seminggu sebelum musim panen, pedagang-pedagang yang biasa mangkal dalam acara Tiwu Panganten diundang untuk berdagang di UARTP. Setelah syarat terpenuhi, pembantu sadar. Sejak itu, sampai sekarang, UARTP rutin dilaksanakan setiap setahun sakali. Kejadian tersebut merupakan kejadian magis yang tidak terjelaskan secara logis. Wawallhua'alam.

\section{h. Konsep Teater}

UARTP merupakan seni pertunjukan, sebab UARTP ditampilkan di depan masyarakat umum. Adanya panggung (tempat nayaga dan alat gamelan dimainkan), penonton (para tamu undangan dan masyarakat), teks skenario (yang dibuat Bapak H. Sodikin, S.S.) sesuai dengan ketentuan konsep seni teater.

\section{Fungsi UARTP}

\section{a. Bentuk Hiburan (rekreatif)}

UARTP merupakan kegiatan yang mempunyai fungsi hiburan. Ini terbukti dengan banyaknya masyarakat dan pedagang yang ingin menonton, mereka tonton bukan semata nilai ritus upacara tapi sisi keramaian yang jarang ditemukan selain dalam upacara ritus ini.

\section{b. Alat Pengesahan Pranata-Pranata dan Lembaga-Lembaga Kabudayaan (Kultural)}

Tahun 2005 ketika Dinas Pendidikan masih dinaungi oleh Dinas Kebudayaan, Kepala Dinas Kebudayaan Kecamatan Babakan (Bapak Wirsad Budiwiantara) menyatakan bahwa UARTP termasuk pada kebudayaan daerah yang ada di Kecamatan Babakan. Hal tersebut membuktikan bahwa UARTP termasuk edalam pengesahan pranata-pranata dan lembaga kabudayaan yang diakui oleh instansi yang ada hubunganya dengan kebudayaan (kebudayaan kultur masyarakat Babakan). 


\section{c. Bentuk Pendidikan Anak-Anak}

Dalam setiap susunan acaranya, kegiatan UARTP mempunyai nilai-nilai misalnya nilai sosial, moral, dan pendidikan. Diharapkan tradisi UARTP bisa menjadi alat untuk membangun pendidikan khususnya untuk parapelajar agar tidak melupakan tradisinya.

\section{d. Alat Pemaksa atau Pengawas Masyarakat dalam Melaksanakan Norma-Norma Sosial}

UARTP merupakan suatu alat hiburan yang ditunggu-tunggu setiap tahun. Di samping hiburan UARTP mengandung norma-norma sosial di masyarakat. Hubungan sosial antar pegawai PG Tersana Baru, para petani tebu dan masyarakat Babakan akan terasa melalui kegiatan UARTP. Semua unsur merasakan kedekatan dalam kegiatan tersebut.

\section{Nilai Kearifan Lokal yang ada dalam UARTP di Kecamatan Babakan Kabupaten Cirebon.}

Nilai kearifan lokal mempunyai fungsi yang bisa dikaitkan dengan unsur pelaku dalam kegiatan UARTP. Nilai-nilai kearifan lokal UARTP akan dijelaskan di bawah ini.

\section{a. Kesejahteraan}

Petani tebu akan merasa bahagia jika musim panen tebu tiba, sebab hasil bertanam selama berbulan-bulan akhirnya menuai hasil. Tebu yang dijual ke PG Tersana Baru sudah tentu menghasilkan uang. Dalam hal ini petani merasa sejahtera.

\section{b. Kerja Keras}

Ketika musim panen tiba, para petani dan para pegawai mendadak mempunyai pekerjaan tambahan. Kerja tambahan ini dilakukan untuk mengejar keuntungan.

\section{c. Disiplin}

Dengan dilaksanakannya UARTP secara tidak langsung menjadikan pegawai disiplin dalam bekerja. Pegawai berlombaloba untuk mengejar target, dan mempertahankan kualitas kerjanya, tentu dengan disiplin.

\section{d. Pendidikan}

UARTP merupakan bentuk pendidikan bagi generasi muda (khususnya para pelajar) dan juga sebagai bentuk penjagaan terhadap keberlangsunagn budaya Sunda. Sudah tentu generasi muda mengetahui dan memahami nilai-nilai moral, sosial yang ada dalam kegiatan UARTP.

\section{e. Gotong Royong}

Acara ini tidak akan terlaksana jika tidak adanya kerja keras dan gotong royong antara sesama, baik itu panitia ataupun masyarakat.

\section{f. Pengelolaan Gender}

Dalam pelaksanaan UARTP yang mempunyai peran paling besar adalah lakilaki. Pelaku yang ada dalama UARTP tak lain pegawai PG Tersana Baru yang didominasi oleh laki-laki. Hal ini terlihat dalam iring-iringan petani yang memegang tebu.

\section{g. Upaya Memelihara Budaya}

UARTP adalah salah satu hasil kebudayaan yang tumbuh di lingkaungan PG Tersana Baru Kecamatan Babakan Kabupaten Cirebon. Adanya pelaksanaan upacara ini membuktikan sebuah eksistensi kebudayaan yang tetap dipelihara dan dijaga oleh para pelakunya.

\section{h. Ketenteraman}

UARTP dilaksanakan setiap tahun oleh PG Tersana Baru. Hal ini disebabkan karena adanya kepercayaan akan hal mistis. Masyarakat di daerah ini percaya jika UARTP tidak dilaksanakan maka akan terjadi mamala yang menimpa para pegawai PG Tersana Baru. Oleh karena itu, para pegawai akan merasa tingtrim (tenteram) jika UARTP dilaksanakan sebagai penolak bala. 


\section{i. Sopan Santun}

UARTP merupakan kegiatan yang sakral, artinya ada beberapa kegiatan yang harus dilaksanakan oleh ahlinya. Contohh kegiatan yang sakral adalah dalam acara nyuguh. Acara nyuguh harus dilakukan oleh seorang punduh yang mempunyai keahlian khusus. Tidak sembarang orang untuk memimpin upacara nyuguh. Hal ini merupakan nilai sopan santun dalam kegiatan UARTP yang dilaksanakan oleh PG Tersana Baru. Pemuda tidak bisa melaksanakan tugas jika bukan tugasnya.

\section{j. Kejujuran}

Para pegawai PG Tersana baru diharapkan dalam pelaksanaannya tidak mengambil alat-alat atau segala hal yang dimiliki PG Tersana Baru. Hal itu merupakan tindakan kriminal, tapi di samping itu ada larangan yang tersembunyi dibaliknya. Mereka percaya jika mengambil barang yang dimiliki PG Tersana Baru, yang mengambilnya akan mendapat apes atau celaka. Hal itu menuntut kepada para pelakunya untuk bersikap jujur.

\section{k. Kesetiakawanan Sosial}

Dalam runtuyan acara UARTP para pelaku upacara saling menolong antara pelaku upacara adat dan pelaku upacara lainnya. Ini merupakan nilai kesetiakawanan sosial sebab mereka saling membantu untuk terciptanya pelaksanaan kegiatan UARTP.

\section{l. Karukunan dan Cara Menyelesaikan Konflik}

Dalam pelaksanaan UARTP tentu ada masalah yang mesti dihadapi. Masalahmasalah yang dirasakan baik yang pahit dan yang manis oleh panitia pelaksana akan diselesaikan dalam waktu itu juga. Ini merupakan nilai kerukunan dalam menghadapi konflik.

\section{m. Komitmen}

Dalam kegiatan UARTP para pelaku sudah mendapatkan tugasnya masing- masing. Tugas ini dipercayakan kepada para pelaku, dan harus dikerjakan berdasarkan tugasnya. Kegiatan ini merupakan komitmen para pegawai dalam melaksanakan tugasnya.

\section{n. Pikiran Positif}

Dalam melangsungkan UARTP semua masyarakat berharap musim panen yang akan datang hasilnya akan bertambah. Dilaksanakannya UARTP tentu akan membawa pikiran positip bagi para petani, pegawai, atau PG Tersana Baru.

\section{o. Rasa Sukur}

UARTP merupakan rasa syukur dalam menyambut musim panen agar dalam musim giling tahun sekarang menghasilkan keuntungan untuk petani, pegawai, dan PG Tersana baru. Acara ini ditujukan sebagai ucapan rasa syukur dan kegiatan keselamatan di dalam pabrik gula yang dilaksanakan oleh para kiai, alim ulama, wakil masyarakat, dan para pegawai PG Tersana Baru.

\section{SIMPULAN}

Setelah dilaksanakannya penelitian, terkuak beberapa hal, bahwa UARTP adalah upacara iring-iringan Tebu Pangantin dan beberapa tebu pengiring yang diiring dari Gedung Sanggar Madu (gedong patémon) sampai ke dalam Pabrik Gula Tersana Baru. Rangkaian acara dalam UARTP merupakan unsur struktural dalam satu kebudayaan sebab merupakan susunan unsur-unsur atau bagian untuk mewujudkan rangkaian satu cerita sampai menghasilkan wujud karya yang mempunyai makna. Dalam UARTP terdapat unsur semiotik yaitu ilmu yang mempelajari tentang tanda, dan tanda merupakan salah satu hal yang mewakili hal lainnya dalam batas-batas tertentu yang ada dalam UARTP. Simbol yang terkuak dalam UARTP ada 17, indeks yang ada dalam UARTP 51 dan ikon ada 57.

Konsep yang ada dalam UARTP, yaitu konsep-konsep permainan, folklor, ritus, 
mite, punduh, magi, dan teater. Fungsi yang ada dalam UARTP yaitu fungsi hiburan (rekratif), alat untuk pengesahan pranatapranata dan lembaga-lembaga kebudayaan (kultural), alat pendidikan anak, alat pemaksa atau pengawas norma-norma masyarakat. UARTP merupakan satu uapacara ritual Sunda yang merupakan ritus yang sifatnya untuk hiburan, mistis, magi, kejawen, yang diadakannya setahun sekali yang memiliki tujuan untuk keselamatan dan berharap mempunyai hasil yang banyak dalam musim giling tahun sekarang.

Nilai kearifan lokal yang ada dalam UARTP bisa bertahan dalam menghaapi jaman. Budaya-budaya barat yang masuk tidak semuanya baik dan langsung diteima langsung oleh masyarakat Indonesia dan masyarakat Sunda khusunya. Nilai-nilai yang terkuak dalam UARTP yaitu nilai kesejahteraan, kerja keras, pendidikan, kesehatan, gotong royong, pengelolaan gender, memeihara budaya, peduli lingkungan, sopan santun, kejujuran, kesetiakawanan sosial, kerukunan dan cara menyelesaikan konflik, komitmen, pikiran positif, serta rasa syukur.

UARTP diharapkan tetep dipelihara dan dijaga oleh generasi muda. Selain itu, UARTP diharapkan bisa dikenalkan ke masyarakat luar Cirebon sebagai satu dari banyaknya kabudayaan nasional yang harus dijaga dan dilestarikan sebagai dokumen kebudayaan nasional.

\section{PUSTAKA RUJUKAN}

Dananjaja, J. (2002). Folklor Indonesia Ilmu Gosip, Dongeng dan lain-lain. Jakarta: PT. Pustaka Utama Grafiti.

Deanastasia. (2011). tersedia di: www. kaarifan lokal wikapedia.com.2011

Endraswara, S. (2012). Metodologi Penelitian Kebudayaan. Yogyakarta: Gadjah Mada University Press.

Koentjaraningrat. (2009). Pengantar Ilmu Antropologi. Jakarta: Aksara Baru.

Pudentia. (2008). Metodologi Kajian Sastra Lisan. Jakarta: Asosiasi Tradisi Lisan (ATL).

Santosa, P. (1993). Ancangan Semiotika dan Pengkajian Sastra. Bandung: Angkasa.

Sudjiman, P. dan Zoest, A.V. (1996). Serba Serbi Semiotika. Jakarta: Gramedia Pustaka Utama.

\section{UCAPAN TERIMA KASIH}

Penulis mengucapkan terima kasih kepada semua pihak yang terlibat membantu penelitian ini. Kepada seluruh masyarakat yang terlibat dalam UARTP dan kepada dosen-dosen Prodi Bahasa dan Budaya Sunda SPs UPI khususnya dosen pembimbing yaitu Dr. Ruhaliah, M.Hum. dan Dr. H. Dingding Haerudin, M.Pd., penulis menghaturkan terima kasih dan penghargaan setinggi-tingginya.

Terima kasih pula kepada Penyunting Jurnal Lokabasa yang telah berkenan memuat tulisan ini. Semoga bermanfaat. 